\title{
C-11 Choline Positron Emission Tomography and Magnetic Resonance Imaging
}

National Cancer Institute

\section{Source}

National Cancer Institute. C-11 Choline Positron Emission Tomography and Magnetic Resonance Imaging. NCl Thesaurus. Code C148080.

An imaging procedure that combines C-11 choline PET with an MRI scan to overlay activity data onto detailed anatomic images. 